\title{
A Learner's Style and Profile Recognition via Fuzzy Cognitive Map
}

\author{
D.A.Georgiou, D. Makry \\ Department of Electrical and Computer Engineering, School of Engineering, Democritus University of Thrace, 671 \\ 00 Greece \\ e-mail:1georg@ee.duth.gr
}

\begin{abstract}
There is a crucial issue in Adaptive Educational Hypermedia, concerning the machine's ability to recognize the learner's style and profile to the purpose of providing the learning material tailored to the learner's specific needs. In this paper an approach to this problem is presented, based on methodologies one can find in Fuzzy Logic and Neural Networks. The socalled Fuzzy Cognitive Map becomes a powerful tool in this case, as it has been proved in other applications to. The reason, which leads to such approach, is mainly the observation of uncertainty in learner's profile description. Therefore, classes in any classification of learner's profile are considered as fuzzy sets and are represented as vertices of a Fuzzy Cognitive Map.
\end{abstract}

\section{Introduction}

The proposed method of learner's profile and style recognition is based on Fuzzy Cognitive Maps (FCM) which are a soft computing methodology that has been successfully used to model complex systems [1], [2] and to support making decisions Papageorgiou et. Al. [6]. A system designed to diagnose in the best possible way the learner's profile as it has been classified by the experts in the field, can be considered a complex system FCM methodology.

\section{Learner Styles and their Characteristics}

Despite the numerous classifications on the learner's style which have been proposed so far, one easily recognize the difficulty to classify many learners as of a certain kind in any given classification. No matter the classification in hands, the subsets should rather be characterized by their fuzziness than by their compactness. To the purpose of the presentation of a classification by Fuzzy Cognitive Map, we consider as learning style model, introduced by Kolb, according to whom "we learn by conceiving and transforming our experiences". The proposed method can be easily applied to other classifications of learner's style in an analogous manner. According to Kolb's classification, conception and elaboration of information are the two dimensions of learning process. It has also been pointed out that each dimension of the learning process presents us with a choice. For example, it is virtually impossible to drive a car (Concrete Experience) and at the same time to analyze a driver's manual about the car's function (Abstract Conceptualization). Therefore, we resolve the conflict by choosing. Hence, in order to conceive information one has to choose between Concrete Experience and Abstract Conceptualization. As a matter of information elaboration one has to choose among Reflective Observation or Active Experimentation. Such choices determine the learning style. According to Kolb's model, the four learning styles and the corresponding per learning dimension choices are presented at the following table [Jonassen \& Grabowski]. Taking a step further, one should realise the incompleteness of having a concrete classification of the four classes. Diverger and Assimilator have RO in common, as Assimilator has common characteristics to Converger and so .

\section{Fuzzy Cognitive Maps}

Fuzzy Cognitive Maps (FCM) is a soft computing tool which can be considered as a combination of fuzzy logic and neural networks techniques. FCM representation is as simple as an oriented and weighted compact graph. Each vertex of the graph represents a concept which express explicitly or implicitly certain characteristics a learner has, or the main learner styles according to Kolb [5] classification. The vertices of the graph connect pairs of the user characteristics if and only if there is a certain relationship among them. Each con- 
cept is characterized by an integer indicating the significance of the characteristic in the model. So, an integer of great value indicates the importance of the concept, as an integer of low value indicates a concept of minor meaning. In order to transform this values of concept significance into the scale of $[0,1]$, which is in use by the fuzzy logic methods, we introduce an appropriate simple linear transformation. As a matter of fact, the labels which stand for the weights of the graph's

\begin{tabular}{|c|c|c|c|c|}
\hline & 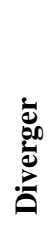 & 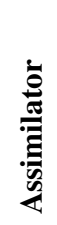 & نे & 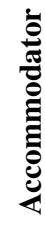 \\
\hline $\begin{array}{c}\text { Active } \\
\text { Experimentation (AE) } \\
\end{array}$ & & & $\mathbf{x}$ & $\overline{\mathbf{x}}$ \\
\hline $\begin{array}{c}\text { Abstract } \\
\text { Conceptualization (AC) }\end{array}$ & & $\mathbf{x}$ & $\mathbf{x}$ & \\
\hline $\begin{array}{c}\text { Reflective } \\
\text { Observation (RO) }\end{array}$ & $\mathbf{x}$ & $\mathbf{x}$ & & \\
\hline $\begin{array}{c}\text { Concrete } \\
\text { Experience } \\
\text { (CE) }\end{array}$ & $\overline{\mathbf{x}}$ & & & $\mathbf{x}$ \\
\hline
\end{tabular}

Table 1

oriented edges, should also be defuzzified and transformed to values in $[-1,1]$. The final graph is designed in a way that easily its observer can see the significance of a concept and the influence each concept has on another. As of the simplicity of its structure, an expert can easily add more vertices and edges in case new concepts should be introduced or more experts are asked to be represented in the model.

\section{The model}

Each class conforms a layer of concepts, colored to a particular color. The inner layer is conformed by the four learner's profiles according to Kolb's classification. The middle layer is the layer of basic learner's characteristics, according to Table 1 .

The outer layer has the measurable learning activity factors (LAF) which are subjects to be diagnosed by the machine. Such factors influence directly the learner's characteristics. The oriented connections between concepts - vertices of the graph are represented by arrows. The connections may show positive or negative influence LAF can have to LCs and LPs. A negative connection reduces the probability to diagnose a certain LP in case of strong presence of a connected LAF.

To explain these approaches the following related definitions are required:

1. the set of elements $C_{i} \in \Theta$, where $\Theta=\{\mathrm{LAF}\} \cup\{\mathrm{LC}\} \cup\{\mathrm{LP}\}$;

2. A, a linguistic term of a linguistic variable (e.g. almost absolute cause) ;

3. A measurable numerical assignment compact interval $\mathrm{X} \in(-\infty, \infty)$;

4. $\mathrm{V} \in \mathrm{X}$, a linguistic variable which is a label for $\mathrm{C}_{\mathrm{i}} \in \Theta$;

5. $\mu \mathrm{A}\left(\mathrm{C}_{\mathrm{i}}\right)$, the membership value representing the degree of membership of $\theta i$ to the set of elements determined by linguistic term A.

Since we do not expect that all LAFs have the same degree of effectiveness and causality on their adjacent LCs and LPs, weights must determined in order to express the degree of effectiveness and causality in case. As cognitive psychology experts mostly describe qualitative behavior using linguistic variables, it is necessary to introduce a transforming algorithm to map the values of such linguistic variables into membership functions. Watanabe's [9] membership functions direct estimation methods take an approach by asking experts to grade an event on a scale. Using such grading, we make use of the transform which appears in Georopoulos et. Al. [3]. According to the proposed scheme, each fuzzy set corresponds to a membership function shown in the figure 2 , where fuzzy sets describe the degree of causality corresponding to membership functions $\mu \mathrm{A}\left(\mathrm{C}_{\mathrm{i}}\right), \mathrm{A}=\{\mathrm{ewc}, \mathrm{wc}, \mathrm{oc}$, sigc, strc, esc, aac .

The proposed fuzzy sets and their corresponding membership functions are:

- $\mathrm{M}_{\text {ewc }}$ (extremely weak cause) the fuzzy set for causality around $10 \%$ with membership function $\mu$ ewc.

- $\quad \mathrm{M}_{\mathrm{wc}}$ (weak cause) the fuzzy set for causality around $20 \%$ with membership function $\mu_{\mathrm{wc}}$.

- $\mathrm{M}_{\mathrm{oc}}$ (ordinary cause) the fuzzy set for causality around $35 \%$ with membership function $\mu_{\mathrm{oc}}$.

- $\mathbf{M}_{\text {sigc }}$ (significant cause) the fuzzy set for causality around $50 \%$ with membership function $\mu$ sigc.

- $\quad \mathrm{M}_{\text {strc }}$ (strong cause) the fuzzy set for causality around $65 \%$ with membership function $\mu_{\text {strc }}$. 
- $\mathrm{M}_{\mathrm{esc}}$ (extremely strong cause) the fuzzy set for causality around $80 \%$ with membership function $\mu_{\text {esc }}$.

- $\quad \mathrm{M}_{\mathrm{aac}}$ (almost absolute cause) the fuzzy set for causality around $90 \%$ with membership function $\mu_{\text {aac. }}$

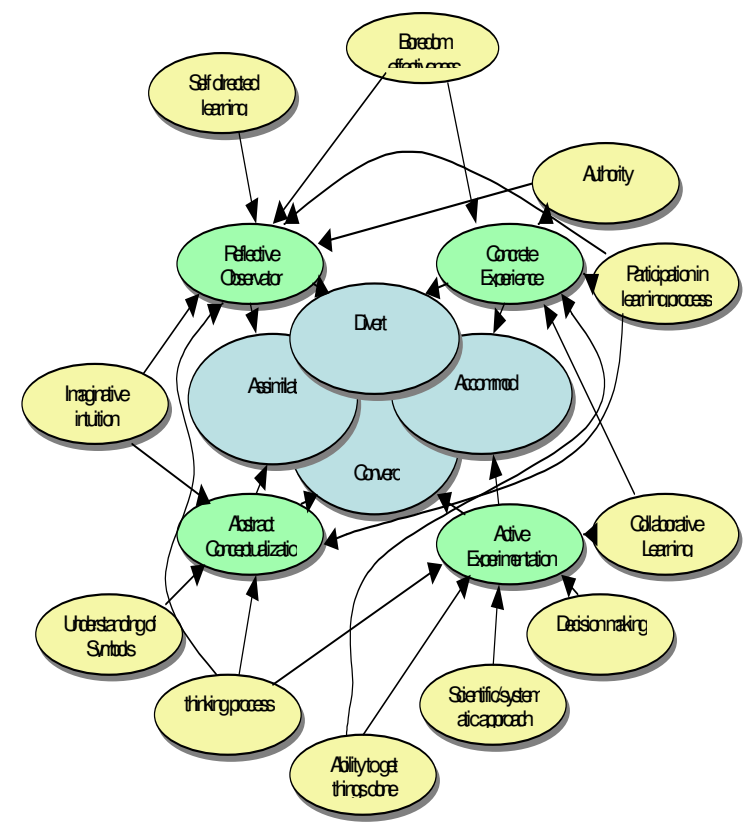

Figure 1

For example when considering the set of learners characteristic for a given ${ }_{\mathrm{Ci}}$ (e.g. the specific learner's Synthetic Ability) in the set $\Theta=L C$, whose linguistic value $\mathrm{V}$, describes the 'degree (A) of learner's characteristic', has. For example the 'degree of learner's characteristic' might be in the range of evaluation units $\mathrm{X}$ $=[0,10]$. Moreover, how 'Active Experimentator' the learner's Synthetic Ability might be, is the value of the membership function $\mu$ strc(Active Experimentation).

Direct rating presents randomly selected $\theta \mathrm{i} \in \Theta$, with values $\mathrm{V}(\theta \mathrm{i}) \in \mathrm{X}$ to subjects who answer the question "How $\mathbf{A}$ is $\theta(\mathrm{V}(\theta))$ ?" . In other words the question put to the expert is "How much reflective observator is learner $\theta$ ?" (Note that 'significant causal ' is different from 'causal') and they respond by using a simple indicator on a sliding scale. Then, using the experts' opinion of the range of causality, a simple calculation re- veals $\mu_{\text {strc }}($ learner $\theta \mathrm{i})$. This experiment is repeated for other learner and, indeed, the same learner $\theta \mathrm{i}$ repeatedly to reduce error. In the late case, experimental outputs are summed up and using the defuzzification method CoA, is transformed into a numerical value which takes place for the weight $\mathrm{W}_{\theta, \mathrm{i}}$.

\section{The Algorithm}

Let $\mathrm{N}$ be the number of concepts in the FCM

- Set the number $\mathrm{k}$ of learners

- Set initial values $n=0, V^{0}\left(C_{i}\right)$ for $i=1,2,, N$ from the learner's profile database. Data have been stored as the learner responded to certain tests. Data have been stored as linguistic values $\mathrm{Ai}$, and have been turn to fuzzy degrees $\mathrm{V}^{0}\left(\mathrm{C}_{\mathrm{i}}\right)$ for all concepts except those in LP. Concepts in LP are set equal to 0 for $\mathrm{n}=0$.

- Set the initial values for $\mathrm{w}_{\mathrm{j}, \mathrm{k}}$ according to given information.

- For $n=n+1$, apply the relation (1) and set values $\mathrm{V}^{\mathrm{n}+1}\left(\mathrm{C}_{\mathrm{i}}\right)$. Update learner's profile database. Following the defuzzification the weights at the edges of the graph are presented as elements of the adjacent matrix $\mathrm{W}_{\mathrm{n}}$.

- Set $\mathbf{V}^{\mathrm{n}+1}=\mathrm{W}_{\mathrm{n}} \mathbf{V}^{\mathrm{n}}$, where

- If a $C_{i}$ does not be influenced by any $C_{j}, j \neq i$ then $w \mathrm{j}, \mathrm{i}=1$ at present $\mathrm{n}$

- If a $\mathrm{V}^{\mathrm{n}}\left(\mathrm{C}_{\mathrm{i}}\right)=\mathbf{m}\left[\mathrm{V}^{\mathrm{n}}\left(\mathrm{C}_{\mathrm{j}}\right)\right]^{-1}$, for a given measure of competence $0<m<1$, then set $\mathrm{w}_{\mathrm{i}, \mathrm{j}}=-\mathbf{m}$

- Use the unipolar sigmoid function to transform the coordinates of $\mathrm{V}^{\mathrm{n}+1}$ into the interval $[0,1]$.

If $\max 0<\mathrm{i}<\mathrm{kIV}{ }^{\mathrm{n}+1}\left(\mathrm{C}_{\mathrm{i}}\right)-\mathrm{V}^{\mathrm{n}}\left(\mathrm{C}_{\mathrm{i}}\right) \mid<\varepsilon,(\varepsilon>0)$ then stop and store as result the learner's profile which has the highest value $\mathrm{V}^{\mathrm{n}+1}\left(\mathrm{C}_{\mathrm{i}}\right)$

The second and following pages should begin 1.0 inch $(2.54 \mathrm{~cm})$ from the top edge. On all pages, the bottom margin should be 1-1/8 inches $(2.86 \mathrm{~cm})$ from the bottom edge of the page for $8.5 \times 11$-inch paper; for A4 paper, approximately $1-5 / 8$ inches $(4.13 \mathrm{~cm})$ from the bottom edge of the page.

\section{Conclusions and Future Directions}

The above method has been developed to provide a fully computerized procedure which will be able to diagnose the learner's profile. An Adaptive Educational Hypermedia platform, which supports asynchronous elearning, will take fully advantage of the proposed algorithm, in order to "see" the learner and to tailor the 
learning material to his special needs. This study is considered to be part of the project for the developing of the ATTAIN (Aptitute Treatment Training in Adaptive Instructions) platform.

Alternatively to Watanebe's Direct Esimation Methods, one can apply the Reverse Rating method, introduced by Turksen [8]. As the Reverse rating method takes a different approach by asking an expert to answer the following question "Identify $\theta(\mathrm{V}(\theta))$ that has the $y$-th degree of membership in fuzzy set A." This technique allows a direct use of machine applicable diagnostic tests, which produce certain degree of membership in fuzzy sets, to the purpose of learner's style and characteristics recognition.

Another possible approach to the recognition of learner's profile could be the application of learning methods. Such approach overcomes deficiencies caused by the dependence on human experts and the learner's responses. The introduction of Hebbian algorithm as it has been proposed for FCM by Papageorgiou, Stylios and Groumbos [7], improves the efficiency and robustness of the system.

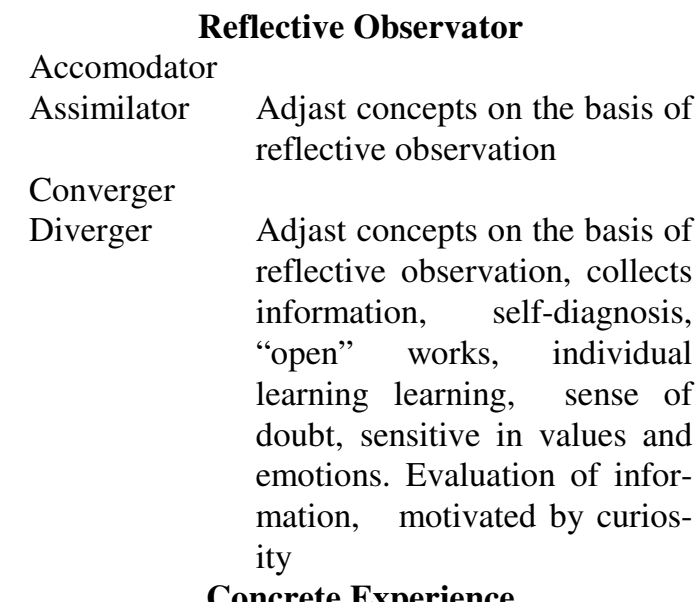

Accomodator

Assimilator

Converger

Diverger

\section{Active Experimentation}

Accomodator Work on concepts on the basis of active experimentation

Assimilator

Converger

Work on concepts on the basis of active experimentation

Diverger

\begin{tabular}{|c|c|}
\hline & \\
\hline comodator & \\
\hline Assimilator & $\begin{array}{l}\text { Focuses on concepts which are } \\
\text { result of abstract conceptuali- } \\
\text { sation, organise information in } \\
\text { several interesting ways, con- } \\
\text { trol on theories and concepts } \\
\text { Design of experiments. Analy- } \\
\text { sis of quantitative data. }\end{array}$ \\
\hline Converger & $\begin{array}{l}\text { Focuses on concepts which are } \\
\text { result of abstract conceptuali- } \\
\text { sation, establishes conceptual } \\
\text { models. }\end{array}$ \\
\hline
\end{tabular}

Diverger

Diverger

Less oriented towards thinking

Converger

Accommodator

Deduction

Assimilator

Concrete 2 Abstract

induction

\section{Participation in learning process}

Diverger

Converger

Practice

Accommodator

Select info

Assimilator

Hands on tasks

organize

Understanding symbols and abbreviation

Diverger

Converger

Accommodator

Needs concrete examples

Assimilator

Very good

Good

maximum

\begin{tabular}{ll}
\multicolumn{2}{r}{ Boredom effectiveness /patience } \\
Diverger \\
Converger \\
Accommodator & minimum \\
Assimilator & Maximum
\end{tabular}

Adapt ideas from concrete experience, collects information, self-diagnosis, "open" works, individual learning, sense of doubt, sensitive in values and emotions.Evaluation of information, motivated by curiosity 


\section{Self directed learning vs guidance need}

Diverger

Converger

Accommodator

Assimilator
Very good at self directed learning / self diagnostic

Good at self directed learning

Needs guidance

Maximum
Authority

Diverger

Converger

Accommodator

Assimilator
Doubts

Scepticism

Seeks for

appreciate

\begin{tabular}{ll}
\multicolumn{2}{c}{ Ability to get things done } \\
$\begin{array}{l}\text { Diverger } \\
\text { converger }\end{array}$ & $\begin{array}{l}\text { Very good/ apply } \\
\text { ideas } \\
\text { Carries out plans } \\
\text { Rather hesitant } \\
\text { Assimilator }\end{array}$ \\
\multicolumn{2}{c}{ Emotionally involved } \\
Oriverger \\
$\begin{array}{l}\text { Onverger } \\
\text { Accommodator } \\
\text { Assimilator }\end{array}$
\end{tabular}

Table 2

\section{References}

[1] Craiger J.P. et, al., Modeling Organizational Behavior with Fuzzy Cognitive Maps, Intern. Journal of Computational Intelligence and Organizations, (1996) p.p 120-123

[2] Dickerson J.A. \& Kosko B., Virtual Worlds in Fuzzy Cognitive Maps, Fuzzy Engineering, editor B. Kosko, Prentice-Hall, Upper Saddle River, New Jersey, 1997

[3] Georgopoulos V., Malandraki G., Stylios Ch., A Fuzzy Cognitive Map Approach to Differential Diagnosis of Specific Language Impairment, Artificial Intelligence in Medicine, 29 (2003), 261-278

[4] Jonassen D., Grabowski B., Handbook of individual differences learning and instruction (1992), Lawrence Erlbaum Associates.

[5] Kolb, D. A. "Experiential learning: Experience as the source of learning and development."(1984). New Jersey: Prentice-Hall.

[6] Papageorgiou E.I., Stylios C.D., Groumpos P.P. An integrated two-level hierarchical system for decision making in radiation therapy based on fuzzy cognitive maps, IEEE Transactions on Biomedical Engineerinng (2003) 50 (12) p p. 1326-1339

[7] Papageorgiou E.I., Stylios C.D., Groumpos P.P. Fuzzy Cognitive map Learning Based on Nonlinear Hebbian Rule, A.I.2003: Advances in Artificial Intelligence - Lecture Notes in A.I.

[8] Turksen I.B.. Measurement of membership functions and their acquisition. Fuzzy Sets and Systems, 40:5--38, 1991.

[9] Watanabe N. Statistical Methods for Estimating Membership Functions. Japanese Journal of Fuzzy Theory and Systems, 5(4), 1979. 